\title{
Narcissism in Public Accounting Firms
}

\author{
Dr. Michael D. Akers ${ }^{1}$, Dr. Don E. Giacomino ${ }^{2} \&$ Jill Weber $^{3}$ \\ ${ }^{1}$ CPA, CMA, CFE, CIA, Charles T. Horngren Professor and Department Chair, Department of Accounting, College \\ of Business Administration, Straz Hall 303, Marquette University, Milwaukee, WI 53201, USA \\ ${ }^{2}$ CPA, Professor and Flynn Chair Holder, Department of Accounting, College of Business Administration, Straz \\ Hall 303, Marquette University, Milwaukee, WI 53201, USA \\ ${ }^{3}$ Doctoral Candidate, Oklahoma State University, USA \\ Correspondence: Dr. Michael D. Akers, CPA, CMA, CFE, CIA, Charles T. Horngren Professor and Department \\ Chair, Department of Accounting, College of Business Administration, Straz Hall 303, Marquette University, \\ Milwaukee, WI 53201, USA. Tel: 1-414-288-1453. E-mail: michael.akers@marquette.edu
}

Received: July 22, 2014

Accepted: August 15, 2014

Online Published: August 19, 2014

doi:10.5430/afr.v3n3p170

URL: http://dx.doi.org/10.5430/afr.v3n3p170

\begin{abstract}
Similar to other characteristics, narcissism is a personality trait that varies by individuals. While the management literature has examined narcissism, there is limited research of narcissism of professionals in public accounting firms. Using the Narcissistic Personality Inventory (NPI), we assess the level of narcissism in practitioners of public accounting firms by examining differences by gender, age, practice area and position. We also compare our results with a prior study that examined narcissism of accounting majors. Our findings show there are differences between accounting students and accounting professionals for certain traits and gender. We also find there are differences for professionals by age, practice area and position for certain traits. Implications for practice are discussed.
\end{abstract}

Keywords: Narcissism, Public accounting, Firms

\section{Introduction}

It is well documented in the literature that the term "narcissism" comes from the Greek myth of Narcissus, a young man who fell in love with his own image and felt he was better than anyone else. Narcissism is considered a personality disorder by clinical psychology researchers (Brunell et al, 2008) while researchers in personality psychology consider narcissism a normal personality trait. Since a narcissistic personality disorder is rare and impacts less than $1 \%$ of the population (Brunell et al., 2008), our study examines the normal personality trait which views narcissism as an individual difference variable. Narcissism includes both positive and negative traits.

The purpose of this paper is to examine narcissism among practitioners of public accounting firms. While accounting research has examined other personality traits and management related research has examined narcissism, we found only two studies (Hill 2005; Banimahd, Dilami and Javanmard, 2013) that addressed narcissism of public accountants and one study that examined narcissism of accounting students (Brown, Akers and Giacomino, 2013). Hill examined corporate narcissism of public accountants in Australia while Banimahd, Dliami and Javanmard examined narcissism of Iranian public accountants employed by governmental and private audit firms. Brown, Akers and Giacomino examined narcissism of Beta Alpha Psi students at two (one private and the other public) Midwestern universities. Our study contributes to the literature by examining narcissistic personality traits of members of U.S. public accounting firms. In addition to the limited research on narcissism in public accounting, we were motivated, in part, by the suggestion in Business Day 2011 that indicated the finance profession includes a disproportionate number of pathological narcissists. While the accounting and finance professions differ, there are also a lot of similarities.

Following this introduction, we examine pertinent prior literature to explain how narcissism is relevant to public accounting. Next, we describe our study and analyze the results. As part of our analysis we also compare our findings with a recent study of narcissism personality traits of accounting students at a private and a public university. We conclude by summarizing our results and discussing the implications of our findings for the public accounting profession. 


\section{Literature Review}

Prior research (Brunell et al, 2008, p. 1664) identifies three basic characteristics of narcissism: 1) positive and inflated views of self; 2) positive self-view at the expense of others and 3) interpersonal relationships that lack warmth and intimacy. If professionals in a public accounting firm exhibit these characteristics, it will impact how they interact with each other and client personnel, as well as how they process, evaluate and summarize information and form conclusions. For example, research has shown that narcissists are very socially skilled (Watson and Biderman, 1994), socially extraverted (Oltmanns et al., 2003), entertaining (Paulhaus, 1998), energetic (Raskin and Terry, 1988), skilled at initiating relationships (Brunell et al., 2008), and well-liked by others during initial encounters (Oltmanns et al., 2003) and that they are likely to have short-term victories in competitive tasks (Campbell, et al., 2005) and strive to associate with high-status individuals (Campbell, 1999). Such characteristics can be very beneficial during initial meetings and discussions as well as the proposal of services with prospective clients as such activities are normally with board members and/or executive management. The initial liking, however, diminishes over time (Paulhus, 1998) and suggests that those individuals in the proposal stage might not be best suited for managing the engagement which includes less glamorous tasks. Narcissists tend to perform well when there is an opportunity to be recognized, however they underperform when the opportunity for recognition doesn't exist (Wallace and Baumeister, 2002). Also, when working with others, they often ignore the value provided by team members while placing too much value on their contributions. (Campbell et al., 2000, Farwell and Wohlwend-Lloyd, 1998, John and Robins, 1994). Such attributes can be beneficial during engagement proposals or initial encounters with a prospective client. Negative aspects of narcissism include distorted judgments of one's abilities (Twenge et al. 2008), risky decision making (Twenge et al. 2008) and white collar crime (Bickel et al., 2006). These attributes can lead to erroneous conclusions that might create business risk through litigation or sanctions by regulatory bodies such as the PCAOB. Prior research also shows that narcissistic traits increase with generations (Twenge, 2008) and there is considerable research (Brunell et al., 2008) that finds narcissists seek leadership roles. This suggests that we might find differences in narcissistic traits by professional level (staff, senior, manager, and partner). Gender research (Tschanz, Morf and Turner, 1998) indicates that there are differences between females and males, particularly with respect authority, exploitiveness, self-sufficiency and entitlement. These gender differences impact how public accounting firms manage and develop their personnel.

\section{Research Design}

Since this study is exploratory in nature we examine the following research question:

1) Do differences exist, by overall score and trait, between public accounting professionals?

\subsection{Sample}

Six public accounting firms (three Big Four; one top 10; and two top 25) in the Midwest agreed to participate in the study. We mailed the Narcissistic Personality Inventory (NPI-see following discussion) to our contact at each of the firms and he/she distributed the NPI to their professionals. Postage-paid envelopes were provided for each instrument so that the professional could respond anonymously. We mailed 784 instruments and received useable responses from 279 accounting professionals resulting in a response rate of $35.6 \%$. Table 1 provides a breakdown by gender, rank, area of practice and age.

Table 1. Demographic Results

\begin{tabular}{|c|c|c|c|c|c|c|c|}
\hline Gender & $\#$ & $\underline{\text { Rank }}$ & \# & Practice & $\#$ & $\underline{\text { Age }}$ & \# \\
\hline Males & 141 & Partner & 40 & Advisory & 22 & $20-25$ & 69 \\
\hline Females & 134 & Manager & 61 & Audit & 155 & $26-30$ & 63 \\
\hline \multirow[t]{5}{*}{ Total } & $\underline{275}$ & Senior & 75 & Tax & 61 & $31-35$ & 38 \\
\hline & & Associate & $\underline{62}$ & Other & $\underline{10}$ & $36-40$ & 29 \\
\hline & & Total & $\underline{\underline{238}}$ & Total & $\underline{\underline{248}}$ & $41-45$ & 19 \\
\hline & & & & & & Over 45 & 36 \\
\hline & & & & & & Total & 4 \\
\hline
\end{tabular}

\subsection{Methodology}

The most common measures of narcissism are the Narcissistic Personality Inventory (NPI) and the Millon Clinical Multiaxial Inventory (MCI). The MCI measures narcissistic personality disorder and the NPI measures narcissism as it occurs in the general population (i.e., "normal narcissism"). We use the NPI to measure "healthy narcissism" (not "pathological narcissism") because the NPI is the most widely used measure of healthy narcissism in social psychological research. 
Although several versions of the NPI have been proposed in the literature, a forty-item forced-choice version (Raskin \& Terry, 1988) is the one most commonly employed in current research. The NPI is based on the DSM-III clinical criteria for narcissistic personality disorder (NPD), although it was designed to measure these features in the general population. Thus, the NPI is often said to measure "normal" or "subclinical" (borderline) narcissism (i.e., people who score very high on the NPI do not necessarily meet criteria for diagnosis with NPD).

The NPI (see Exhibit 1) consists of 40 questions. Each question has two choices (A or B) for respondents to select from. Respondents can determine their score by assigning one point for each response that matches the key. One point is received for selecting the answer " $\mathrm{A}$ " for the following questions $(1,2,3,6,8,11,12,13,14,16,21,24,25,27,29,30,31,33,34,36,37,38$,and 39) and one point is received for selecting answer "B" for all other questions. A respondent's total score is the sum of the matched A and B responses. The average NPI scores for the general population in the United States and for celebrities are 15.3 and 17.8, respectively (Young \& Pinsky, 2009).

Responses are grouped into seven component traits as shown below:

$\underline{\text { Trait }}$ Questions (answered according to key, 1 point for each question)

Authority $1,8,10,11,12,32,33,36$

Self-sufficiency

$17,21,22,31,34,39$

Superiority $4,9,26,37,40$

Exhibitionism

$2,3,7,20,28,30,38$

Exploitiveness

$6,13,16,23,35$

Vanity

$15,19,29$

Entitlement

$5,14,18,24,25,27$

Prior research (Raskin and Terry, 1988; Emmons, 1984) has examined the overall validity of the NPI as well as the validity of the components. Young \& Pinsky (2009) note that in evaluating the results, the overall and the scores for the seven traits should be considered as it is important to consider which traits are dominant. For example, they comment that an individual that scores higher on vanity, entitlement, exhibitionism and exploitiveness is more concerning than a person who scores higher on authority, self-sufficiency and superiority.

Using principal components analysis to test the instrument, Raskin and Terry (1988) concluded that their findings supported the construct validity of the NPI and the components. Emmons (1984) reported on three studies, one of which included factor analysis, which were conducted to evaluate the validity of the NPI. He concluded that the results of the studies supported the construct validity of the NPI.

\section{Results and discussion}

Table 2 below shows the NPI scores and scores for each of the seven traits of narcissists, for the professionals that participated in the study along with the results of the Brown, Akers and Giacomino (2013) study of accounting students. The total NPI average for the accounting professionals is 14.65 which is less than the 15.75 NPI average for accounting majors (Brown, Akers and Giacomino et al. 2013). The accounting professionals score is also less than the averages for the general population (15.3), MBA students (16.18) and celebrities (17.84) (Young and Pinsky, 2009). Results by trait show that the students have higher scores for four of the seven traits. These findings aren't surprising. The majority of prior research suggests that narcissistic traits increase with generations.

Table 2. Average NPI and Trait* Scores for Accounting Professionals and Accounting Students

\begin{tabular}{lllllllll}
\hline & $\begin{array}{l}\text { NPI } \\
\text { Score }\end{array}$ & Auth & Self-Suff & Super & Exhibit & Exploit & Vanity & Entitle \\
\hline Students & 15.75 & 4.68 & 2.90 & 2.03 & 1.68 & 1.70 & 1.04 & 1.72 \\
Professionals & 14.65 & 4.80 & 2.42 & 2.03 & 1.20 & 1.60 & 0.84 & 1.76 \\
\hline
\end{tabular}

*Auth = Authority, Self-Suff $=$ Self-Sufficiency, Super $=$ Superiority, Exhibit $=$ Exhibitionism, Exploit $=$ Exploitiveness, Entitle = Entitlement

Table 3 below shows the average NPI and Trait scores by gender for the professionals participated in the study. 
Table 3. Average NPI and Trait* Scores By Gender

\begin{tabular}{ccccccccc}
\hline & $\begin{array}{c}\text { NPI } \\
\text { Score }\end{array}$ & Auth & Self-Suff & Super & Exhibit & Exploit & Vanity & Entitle \\
\hline Gender & & & & & & & & \\
Males & $15.96^{* *}$ & $5.21^{* *}$ & $2.58^{* *}$ & 2.18 & 1.21 & $1.79 * *$ & 0.91 & $2.08^{* *}$ \\
Females & $13.22^{* *}$ & $4.34^{* *}$ & $2.25^{* *}$ & 1.87 & 1.16 & $1.40^{* *}$ & 0.76 & $1.45^{* *}$ \\
\hline
\end{tabular}

*Auth $=$ Authority, Self-Suff $=$ Self-Sufficiency, Super $=$ Superiority, Exhibit $=$ Exhibitionism, Exploit $=$ Exploitiveness, Entitle $=$ Entitlement

** = Significant differences at the .05 level.

Among professional accountants, we found that on average, men have higher overall NPI scores than women. It is interesting to note that Banimahd, Dilami and Javanmard (2013) did not find significant differences between female and male auditors while our results show significant differences between the groups for the NPI score and four (authority, self-sufficiency, exploitatitiveness and entitlement) traits and Brown, Akers and Giacomino (2013) findings show female accounting students had higher NPI scores than males although the difference was not significant. They only found significant differences on two traits (vanity, entitlement). In addition to the overall NPI score, men exhibited higher scores in the authority, self-sufficiency, exploitiveness, and entitlement traits. Women's lower scores in authority and self-sufficiency is consistent with gender research (Tschanz, Morf and Turner, 1998) and suggests that female accountants may fear negative evaluations by exhibiting such traits. Therefore, it may be in public accounting firms' best interest to continue or expand mentoring programs designed to help female accountants develop leadership skills, pursue leadership opportunities, and develop confidence in their abilities. Women's lower scores in self-sufficiency may also indicate that female accountants are more likely to place higher value on the contributions of their teammates. Male accountants' higher scores in exploitiveness and entitlement is consistent with gender/psychology research (Tschanz, Morf and Turner, 1998) that suggests that females would be negatively impacted by having higher scores in these area as females are expected to be more understanding and compassionate. Public accounting firms should consider how these gender differences impact their development, training and evaluation programs.

NPI scores and scores by trait by age group are shown in Table 4 . These scores appear to vary inversely with age. The data show, as they age, the accounting professionals become less narcissistic. The youngest professionals had the highest NPI scores and the highest scores for traits. It is interesting to note that the youngest professionals (20-25) have a higher NPI score and higher scores for six of the seven traits than the students in the Brown, Akers and Giacomino (2013) study. While this seems inconsistent with the expectation that the students would have higher scores, the differences in the samples might explain this result. Our findings for the overall score is consistent with research that suggests narcissistic traits increase with generations. The age group 20-25 years of age had the highest NPI score (17.00) of all the age groups and the highest score for six (all but self-sufficiency) of the seven traits. The 26-30 group had the highest score for self-sufficiency. The oldest group (over 45 years of age) is the least narcissistic with the lowest NPI score and the lowest scores for five of the seven traits.

We used t-tests to compare each age group with the subsequent age groups. The significant differences (.05 level) are shown in Table 5. These findings illustrate there are greater significant differences between the youngest age group (20-25) and subsequent age groups than any other comparison of age groups.

Table 4. Average NPI and Trait* Scores By Age

\begin{tabular}{ccccccccc}
\hline & $\begin{array}{c}\text { NPI } \\
\text { Score }\end{array}$ & Auth & Self-Suff & Super & Exhibit & Exploit & Vanity & Entitle \\
\hline Age & & & & & & & & \\
$\mathbf{2 0 - 2 5}$ & 17.00 & 5.17 & 2.42 & 2.32 & 1.81 & 1.96 & 1.41 & 1.91 \\
$\mathbf{2 6 - 3 0}$ & 14.97 & 4.83 & 2.60 & 2.05 & 1.22 & 1.63 & 0.80 & 1.84 \\
$\mathbf{3 1 - 3 5}$ & 12.55 & 4.53 & 2.05 & 1.68 & 0.74 & 1.39 & 0.58 & 1.58 \\
$\mathbf{3 6 - 4 0}$ & 13.76 & 4.79 & 2.48 & 2.00 & 0.93 & 1.17 & 0.66 & 1.72 \\
$\mathbf{4 1 - 4 5}$ & 13.58 & 4.53 & 2.53 & 1.84 & 1.00 & 1.37 & 0.58 & 1.74 \\
Over 45 & 12.69 & 4.39 & 2.25 & 1.89 & 0.78 & 1.53 & 0.33 & 1.53 \\
\hline Authority, Self-Suff = Self-Sufficiency, Super = Superiority, Exhibit = Exhibitionism, Exploit =
\end{tabular}

Exploitiveness, Entitle $=$ Entitlement 
Table 5. Significant Differences between Age Groups

\begin{tabular}{|c|c|}
\hline Age Group(s) Diff. Signif. & Variable(s) \\
\hline $20-25$ and $26-30$ & NPI, Exhibitionism, Vanity \\
\hline $20-25$ and $31-35$ & NPI, Supervision, Exploitiveness, Vanity \\
\hline $26-30$ & NPI \\
\hline $20-25$ and $36-40$ & NPI, Exhibitionism, Exploitiveness, Vanity \\
\hline $26-30$ and $36-40$ & None \\
\hline $31-35$ and $36-40$ & None \\
\hline $20-25$ with $41-45$ & NPI, Exploitiveness, Vanity \\
\hline $26-30$ and $41-45$ & None \\
\hline $31-35$ and $41-45$ & None \\
\hline $36-40$ with $41-45$ & None \\
\hline $20-25$ with $>45$ & NPI, Exhibitionism, Vanity \\
\hline $26-30$ and $>45$ & Vanity \\
\hline $31-45$ and $>45$ & None \\
\hline $36-40$ and $>45$ & None \\
\hline $41-45$ and $>45$ & None \\
\hline
\end{tabular}

The NPI and trait scores by practice area are shown in Table 6. The advisory group had the highest NPI score followed by auditing. Since advisory engagements typically are not required for regulatory purposes, such as the financial statement audit or tax return, advisory professionals must continually demonstrate the value of their services to a client. In these circumstances, positive narcissistic traits such as self-esteem, socially skilled, overconfidence/positive affect, assertiveness and well-developed skills at initiating relationships are beneficial. Research has also shown that narcissists are well liked during initial encounters, an important attribute while proposing services to a potential client. Since an audit engagement team typically has more interaction with the client than the tax engagement team we aren't surprised that auditors have a higher NPI score than tax professionals. In addition, the advisory group had the highest scores for five of the seven traits. On self-sufficiency, advisors (2.55) scored slightly lower than the auditors (2.60). On superiority, while the category, "other" had the highest score followed by audit, advisory and tax, the differences are not statistically significant.

Table 6. Average NPI and Trait* Scores By Practice Area

\begin{tabular}{ccccccccc}
\hline & NPI & Auth & Self-Suff & Super & Exhibit & Exploit & Vanity & Entitle \\
\hline Score & & & & & & & & \\
Practice area & & & & & & & & \\
Advisory & 16.59 & 5.27 & 2.55 & 2.05 & 1.45 & 1.82 & 1.09 & 2.36 \\
Audit & 15.32 & 5.03 & 2.60 & 2.15 & 1.17 & 1.63 & 0.91 & 1.84 \\
Tax & 13.72 & 4.60 & 2.17 & 1.84 & 1.30 & 1.49 & 0.68 & 1.63 \\
Other & 13.00 & 3.80 & 1.70 & 2.40 & 1.20 & 1.60 & 1.00 & 1.30 \\
\hline
\end{tabular}

*Auth $=$ Authority, Self-Suff $=$ Self-Sufficiency, Super $=$ Superiority, Exhibit $=$ Exhibitionism, Exploit $=$ Exploitiveness, Entitle $=$ Entitlement

We used to t-tests to identify significant differences between the three major practice areas: advisory, audit, tax. We didn't include "other" in this analysis because of the variety of positions indicated. The only significant differences (.05 level) were between audit and tax for the overall NPI and the trait, sufficiency.

Table 7 shows the average NPI and trait scores by professional level. Except at the partner level, NPI scores varied inversely with level. In other words, moving up from the associate to senior to manager, the NPI average scores decreased. However, at the partner level scores increased and were highest of the four ranks. Some of this difference can be explained by the high scores that partners had for authority and self-sufficiency and partners were not the lowest for any of the other traits. Also, this finding is consistent with research that shows narcissists desire leadership positions. Associates had the second highest total NPI scores and the highest scores for three of the traits; superiority, exhibitionism and vanity. Overall, the results are in agreement with research that the younger professionals (most likely in the associate and senior levels) show higher narcissism traits than the older professionals. 
Table 7. Average NPI and Trait* Scores By Professional Level

\begin{tabular}{ccccccccc}
\hline & $\begin{array}{c}\text { NPI } \\
\text { Score }\end{array}$ & Auth & Self-Suff & Super & Exhibit & Exploit & Vanity & Entitle \\
\hline Prof. Level & & & & & & & & \\
Partner & 15.90 & 5.63 & 2.80 & 2.05 & 1.00 & 1.58 & 0.65 & 2.20 \\
Manager & 13.45 & 4.69 & 2.35 & 1.96 & 0.85 & 1.39 & 0.57 & 1.64 \\
Senior & 14.45 & 4.56 & 2.35 & 1.96 & 1.19 & 1.83 & 0.79 & 1.79 \\
Associate & 15.44 & 4.68 & 2.35 & 2.17 & 1.70 & 1.64 & 1.25 & 1.66 \\
\hline
\end{tabular}

*Auth = Authority, Self-Suff $=$ Self-Sufficiency, Super $=$ Superiority, Exhibit $=$ Exhibitionism, Exploit $=$ Exploitiveness, Entitle = Entitlement

We used t-tests to compare each professional level (rank) with the other professional levels. The significant differences (.05 level) are shown in Table 8.

Table 8. Significant Differences between Professional Levels

$\begin{array}{ll}\text { Group Difference Signif. } & \text { Variables } \\ \text { Partners and Managers } & \text { NPI and Authority } \\ \text { Managers and Seniors } & \text { Authority and Exploitiveness } \\ \text { Partners and Associates } & \text { Authority and Vanity } \\ \text { Managers and Associates } & \text { NPI, Exhibitionism and Vanity } \\ \text { Seniors and Associates } & \text { Exhibitionism and Vanity }\end{array}$

\section{Summary and Conclusions}

In summary, overall, the accounting professionals show slightly lower narcissism scores than the accounting students in the Brown, Akers and Giacomino (2013) study. Students also score higher on four of the seven traits, but the differences were significant for only two traits, self-sufficiency and exhibitionism.

Among professional accountants, the greatest differences in narcissism scores are between age groups. For both the NPI scores and the seven traits, the youngest accounting professionals are most narcissistic and narcissism scores decline with age. Many differences in scores for the traits are statistically significant. The next greatest difference is between males and females, with males showing higher NPI scores (significant) and higher scores for six of the seven traits (the seventh was a tie). Four of the differences for traits are significant. Males are more authoritarian, self-sufficient and exploitative and they have a greater sense of entitlement.

Results by professional level are the most interesting. As professional accountants progress from Associate to Senior to Manager, they become less narcissistic (NPI scores and the scores for most of the traits decline). However, at the Partner level, a reversal occurs; NPI scores and trait scores (authority, self-sufficiency and entitlement) increase significantly above the other ranks. Associates scored highest among the ranks on three traits, superiority, exhibitionism and vanity.

Differences by practice area are the smallest of all the groups tested. Tax professionals had significantly lower NPI scores than auditors and advisors and advisors scored higher than the other professionals on five of the traits. However, the trait differences were not statistically significant.

\section{Implications for the Profession}

While much has been written about generational differences, for the participants in this study and the student study, our findings provide additional support for this premise and show that narcissistic traits are greater in younger generations, with the exception at the partner level. This is important for those that manage younger professionals as well as those that serve as their mentors. Also, firms could evaluate the narcissistic traits of those that are being considered for promotion to partner. Our results also show that narcissistic traits differ by practice area. Firms could use the NPI to evaluate narcissistic traits during the hiring process to aid in the determination of the appropriate practice area. Since the student study showed females had a higher NPI score than males, yet the professionals' results is the opposite, we encourage firms to use the NPI to evaluate the narcissistic traits of women throughout their 
career to determine if further mentoring is necessary to enhance their advancement to leadership positions. The NPI can be completed quickly, yet provide additional insights about personality traits.

\section{References}

Banimahd, B., Dilami, Z. \& Javanmard, M. (2013). Narcissism in Iranian Auditing Profession. Management Science Letters, 3(5), 1421-1426. http://dx.doi.org/10.5267/j.msl.2013.04.006

Bickel, G., Schlegel, A. Fassbender, P. \& Kein, U. (2006). Some Personality Correlates of Business White-Collar Crime. Applied Psychology: An International Review, 55, 220-233. http://dx.doi.org/10.1111/j.1464-0597.2006.00226 .x

Brown, J., Akers, M. D. \& Giacomino, D. E. (2013). Narcissism and Accounting Majors. American Journal of Business Education, May/June 2013, Vol. 5, Number 5. 1-11.

Brunell, A. B., Gentry, W. A., Campbell, W. K., Hoffman, B. J., Kuhnert, K. W. \& DeMarree, K. G. (2008). Leader Emergence: The Case of the Narcissistic Leader. Personality and Social Psychology Bulletin, 34, 1663-1676. http://dx.doi.org/10.1177/0146167208324101

Campbell, W. K. (1999). Narcissism and Romantic Attraction. Journal of Personality and Social Psychology, 77, 1254-1270. http://dx.doi.org/10.1037/0022-3514.77.6.1254

Campbell, W.K., Bush, C. P., Brunell, A. B. \& Shelton, J. (2005). Understanding the Social Costs of Narcissism: The Case of the Tragedy of the Commons. Personality and Social Psychology Bulletin, 31, 1358-1368. http://dx.doi.org/10.1177/0146167205274855

Campbell, W. K., Reeder, G. D., Sedikides, C. \& Elliot, A. J. (2000). Narcissism and Comparative Self-Enhancement Strategies, Journal Research in Personality. 34, 329-347. http://dx.doi.org/10.1006/jrpe.2000.2282

Emmons, R. A. (1984). Factor Analysis and Construct Validity of the Narcissistic Personality Inventory, Journal of Personality Assessment, 48, 291-300. http://dx.doi.org/10.1207/s15327752jpa4803_11

Farwell. L. \& Wohlwend-Lloyd, R. (1998). Narcissistic Processes: Optimistic Expectations, Favorable Self-Evaluations, and Self-Enhancing Attributions, Journal of Personality. 66, 65-83. http://dx.doi.org/10.1111/1467-6494.00003

Hill, V. (2005). Corporate Narcissism in Accounting Firms Australia, Pengus Books.

John, O. P. \& Robins, R. W. (1994). Accuracy and Bias in Self-Perception: Individual Differences in Self-Enhancement and the Role of Narcissism. Journal of Personality and Social Psychology, 66, 206-219. http://dx.doi.org/10.1037/0022-3514.66.1.206

Oltmanns, T. F., Friedman, J. N. W., Fiedler, E. R. \& Turkheimer, E. (2003). Perceptions of People with Personality Disorders Bases on Thin Slices Behavior. Journal of Research in Personality, 38, 216-239. http://dx.doi.org/10.1016/S0092-6566(03)00066-7

Paulhaus, D. L. (1998). Interpersonal and Intrapsychic Adaptiveness of Trait Self-Enhancement: A Mixed Blessing? Journal of Personality and Social Psychology, 74, 1197-1208. http://dx.doi.org/10.1037/0022-3514.74.5.1197

Raskin, Robert \& Terry, H. (1988). A Principal-Components Analysis of the Narcissistic Personality Inventory and Further Evidence of Its Construct Validity. Journal of Personality and Social Psychology, 1988, Vol. 54, No. 5, 890-902. http://dx.doi.org/10.1037/0022-3514.54.5.890

Tschanz, B., Morf, C., \& Turner, C. (1998). Gender Differences in the Structure of Narcissism: A Multi-Sample Analysis of the Narcissistic Personality Inventory. Sex Roles. 38, 9/10, 863-870. http://dx.doi.org/10.1023/A:1018833400411

Twenge, J. M., Konrath, S., Foster, J. D., Campbell, W. K. \& Bushman, B. J. (2008). Egos Inflating Over Time: A Cross-Temporal Meta-Analysis of the Narcissistic Personality Inventory. Journal of Personality, 76:4, 875-901. http://dx.doi.org/10.1111/j.1467-6494.2008.00507.x

Watson, P. J. \& Biderman, M. D. (1994). Narcissistic Traits Scale: Validity Evidence and Sex Differences in

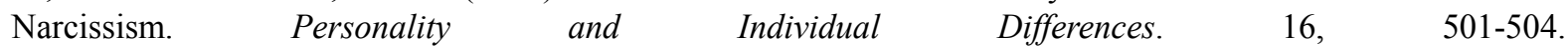
http://dx.doi.org/10.1016/0191-8869(94)90076-0

Young, S. M. \& Pinsky, D. (2009). The Mirror Effect: How Celebrity Narcissism Is Seducing. America. HarperCollins Publishers, New York, NY. 


\section{Exhibit 1 - Narcissistic Personality Quiz}

\section{Based upon the Narcissistic Personality Inventory (NPI)}

Instructions: Below is a list of 40 statements, one in Column A and the opposite in Column B. For each statement, choose the item from Column A or B that best matches you (even if it's not a perfect fit). The quiz takes most people between 5 and 10 minutes to finish. Please respond to all questions.

\section{$\underline{\mathbf{A}}$}

1.

2.

3.

4.

5.

6.

8.

9.

10.

11.

12.

13.

14.

15.

16.

17.

18.

19.

20.

21.

22.

23.

24.

25.

26.
I have a natural talent for influencing people.

Modesty doesn't become me.

I would do almost anything on a dare.

When people compliment me I sometimes get embarrassed.

The thought of ruling the world frightens the hell out of me.

I can usually talk my way out of anything.

I prefer to blend in with the crowd.

I will be a success.

I am no better or worse than most people.

I am not sure if I would make a good leader.

I am assertive.

I like to have authority over other people.

I find it easy to manipulate people.

I insist upon getting the respect that is due me.

I don't particularly like to show off my body.

I can read people like a book.

If I feel competent I am willing to take responsibility for making decisions.

I just want to be reasonably happy.

My body is nothing special.

I try not to be a show off.

I always know what I am doing.

I sometimes depend on people to get things done.

Sometimes I tell good stories.

I expect a great deal from other people.

I will never be satisfied until I get all that I

deserve.

Compliments embarrass me.
$\underline{\mathbf{B}}$

I am not good at influencing people.

I am essentially a modest person.

I tend to be a fairly cautious person.

I know that I am good because everybody keeps telling me so.

If I ruled the world it would be a better place.

I try to accept the consequences of my behavior.

I like to be the center of attention.

I am not too concerned about success.

I think I am a special person.

I see myself as a good leader.

I wish I were more assertive.

I don't mind following orders.

I don't like it when I find myself manipulating people.

I usually get the respect that I deserve.

I like to show off my body.

People are sometimes hard to understand.

I like to take responsibility for making decisions.

I want to amount to something in the eyes of the world.

I like to look at my body.

I will usually show off if I get the chance.

Sometimes I am not sure of what I am doing.

I rarely depend on anyone else to get things done.

Everybody likes to hear my stories.

I like to do things for other people.

I take my satisfactions as they come.

I like to be complimented. 
27.

28.

29.

30.

31.

32.

33.

34.

35.

36.

37.

38.

39.

40.
I have a strong will to power.

I don't care about new fads and fashions.

I like to look at myself in the mirror.

I really like to be the center of attention.

I can live my life in any way I want to.

Being an authority doesn't mean that much to me.

I would prefer to be a leader.

I am going to be a great person.

People sometimes believe what I tell them.

I am a born leader.

I wish somebody would someday write my biography.

I get upset when people don't notice how I look when I go out in public.

I am more capable than other people.

I am much like everybody else.
Power for its own sake doesn't interest me.

I like to start new fads and fashions.

I am not particularly interested in looking at myself in the mirror.

It makes me uncomfortable to be the center of attention.

People can't always live their lives in terms of what they want.

People always seem to recognize my authority.

It makes little difference to me whether I am a leader or not.

I hope I am going to be successful.

I can make anybody believe anything I want them to.

Leadership is a quality that takes a long time to develop.

I don't like people to pry into my life for any reason.

I don't mind blending into the crowd when I go out in public.

There is a lot that I can learn from other people. I am an extraordinary person.

\section{Demographic data}

Gender: __ Female __ Male

Age: 20-25

26-30

31-35

$36-40$

41-45

Above 45

Area of Practice: Advisory Services Audit Tax Other (please indicate)

Position: Partner Manager Senior Associate 